\title{
"WRITING IS HOW I UNDERSTAND THE WORLD": AGEING AND GENDER, QUALITY OF LIFE AND CREATIVITY. AN INTERVIEW WITH LORNA CROZIER
}

\author{
Núria Mina Riera* \\ Universitat de Lleida
}

The interview was conducted throughout two different evenings, at my home, during Lorna's stay in Lleida in November 2019.

NÚRIA: Good evening, Lorna, and thanks for accepting to be interviewed.

LORnA: My pleasure.

NúRIA: So, the first question is, how would you define yourself in terms of identity at present?

LORNA: I've never had any problem with understanding and knowing what it means to be Canadian. I've never had any problem understanding and knowing what it means to be a woman. I think I write from both a Canadian's and a woman's perspective. And now that I'm seventy-one, I guess I could add the adjective "older" Canadian woman; and those would be the three defining terms of my identity as a writer.

NúRIA: All right.

LORNA: And feminist.

NÚRIA: What do you think is the value of ageing into old age?

LORNA: I hope, as I get older, that I'm able to shuck off the inconsequential things in life. I hope that I am able to move further away from ego gratification, from the desire to win awards and prizes, and have my name in the newspaper, and be invited to exotic places. I still would like that to happen, I must admit, but may it become less consequential and less important; and may I fully realize that there is a richer reward to being a writer that goes beyond anyone's or any kind of recognition or praise. I hope that what I do has less to do with pleasing someone else, even a reader, even a literary audience, and has more to do with me, getting closer and closer to some kind of bone truth, some kind of word, or sentence, or thought, or image that I need to say, that could define who I am and get me closer to essential things.

And I hope my speaking and my writing is getting more pared down. I would pray that it's getting more significant, that it's touching something primal

DOI: https://doi.org/10.25145/j.recaesin.2021.82.16

Revista Canaria de Estudios Ingleses, 82; April 2021, pp. 213-226; ISSN: e-2530-8335 
and deep, deep underground like an underwater stream. And it has less to do with the trickling water of what we see and hear above, the sparkly water, the water that lights up someone's face. I would like this water that my words are drawing to the surface to bring light to those who look into it, but to do something else, something darker, too.

NÚRIA: What would be the positive and negative sides of ageing?

LORnA: The negative side of ageing is definitely physical, the fact that the body that you were used to being active with, the body that didn't have aches, and pains and stiffness and fears of being ugly is suddenly starting to suffer from those realities and those fears. It's hard for me to admit that I can't do some of the activities that I used to do with ease. I was a jogger, for instance and, at around forty-five, my knees started to ache and creek, and so instead I became a walker. I walk long distances and I try to walk quickly, but I can't run any more, it's too hard on the joints. Those are the kind of obvious things.

But I know I'm very lucky to be a writer, because one of my good friends is an oboist and she says that her mouth doesn't work the way it used to. It doesn't have the muscle strength and flexibility she spent years of practice working for it to attain. I don't have that problem. As a writer I don't need strong, adept mouth muscles or, if I were a pianist or guitarist, nimble fingers. I just have to hope my mind keeps being sharp, and as long as that's the case, maybe I'll have many years ahead of me as a writer. Some authors write into their eighties and nineties; I would like that creative longevity to be part of my future because writing is how I understand the world. It's my way of getting at what's going on around me, my way of revealing to myself how I feel about things, whether they be joyous or sad. I have to write about what I see and hear and sense, about what I feel. It's my way of being alive. So, whatever gods exist out there, I pray I can keep doing that, up to my last thought, my last feeling, my last breath. You know, Japanese poets are known for writing a death haiku; on their death bed they fashion their last syllables into a poem.

NúRIA: Oh, I didn't know that.

Lorna: Yeah, three lines. Basho has a famous one, and Issa, and Buson, and they spoke these words they'd spent a lifetime preparing for when they were a few breaths away from dying; their disciples wrote them down. Often the haiku weren't what we'd call profound, in the way we in the western world define

* I asked Lorna Crozier to have the following interview for the MINECO Project "Aging, quality of life, and creativity through narrative" (ECAVINAR) [FFI2016-79666-R], as a member of the Research Group Grup Dedal-Lit from the University of Lleida (Spain). ECAVINAR examines the interrelations between literature, writing and active ageing, both in professional and amateur writers. 
profound; they were imagistic, as haikus are. The haiku masters dictated a detail that came from the natural world, a beautiful, small summation of what final smell or vision or touch came to them before they passed away. The profundity comes from brevity and simplicity, at least a surface simplicity, and all the more philosophical implications such concrete details carry with them.

Núria: How humble!

Lorna: How humble! And what a lovely thing to aspire to.

NúRIA: Right. And what about the positive sides of ageing?

LORNA: Now that I'm seventy, I can say things that I might have been cautious about saying before. It's possible for me to be more blunt and people forgive me, I hope, but if they don't, does it matter? As long as I'm not mean, nothing should allow you to be mean. That's a tremendous advantage, you can be more honest, you don't have to worry about pleasing people as much as you used to. This lack of self-censorship can also be kind of fun. You can become a trickster.

And it's a relief to be in a stage where you can admire beauty without longing to possess it or be possessed by it. I can admire a handsome, bright young man like your husband without anything sexual clouding the appreciation. I can just admire, from a distance. I can admire your beauty, Núria, and the beauty of other young human animals and get a warm feeling from it. It doesn't have anything to do with lust or desire, those things so central to my younger self. It just has to do with taking a step back from that and being able to see the gorgeousness that is there, in the human body, in the younger human body. So, that's an advantage, I think.

NúrIA: That's a bit controversial.

LORNA: [laughs]

NÚRIA: Depending on how you read it, but I believe that's very interesting precisely because we can read it in different ways. But I think that if we can maybe nuance it a little bit. Teasing you here, because I know your poems, how about a woman who is older but who actually loves admiring young men and feeling lust for them. What's your opinion on that?

LoRNA: It'd be great to feel attracted, in a sexual way, to a young man (or an older one!). It hasn't happened to me, yet. But I haven't been alone for long, only seven months. I was with a man for forty years, and I adored him and was adored by him in every way. We were lucky to know passion as a man and a woman but also as two writers who chose every day to live together with each other and with words. On the other hand, I like the story of Georgia O'Keeffe, who had a young male assistant. Georgia O'Keeffe, the great American painter. She lived in New Mexico and a man, thirty years her junior I believe, showed up and became her amanuensis and ended up living 
with her. Who knows if they were lovers but, according to all accounts, they were certainly very close. They enjoyed each other's company, whether physically, or intellectually, or artistically, none of our business. But they ended up living together, and he was with her until the day she died. I would not rule out that possibility. And certainly, I don't look forward to dying alone. Does anybody? My husband didn't die alone. I was with him. It's been the tradition in our society that older men have teamed up with younger women, sometimes there's been a thirty-year age gap, and no one thinks anything of it. As a seventy-one-year-old woman, if I fell in love with a forty-year-old man and he with me, that would be terrific, but it would be unusual and probably denounced. I can't imagine it right now, but who knows what's around the corner.

NúRIA: What can you tell me about your own creative process nowadays? In what ways have the methods that you use to write changed or remained the same throughout your life-course?

LORNA: I'm more patient with my silences, particularly after a book comes out. I go through a period where I think I'm never going to write again and I bemoan that this book is the last book. And I used to believe that one hundred per cent, that I'd have nothing more to say, I've said everything. After having written seventeen books, or however many it is, you'd think I'd get used to the fact that yeah, something else is going to happen. I may not know what it is right now or what direction I'm going to move in, but something's gonna happen. So, I don't get as nervous as I used to about my writing being over after the book comes out. I used to feel that panic as a younger writer; I used to be much more impatient. If I didn't start writing immediately after a book tour, for example, I'd think well, that's it, I'm washed out, I'm done.

In my braver moments, I've adjusted to the gaps between books. I'm more used to the silences. I have more faith, I guess, in my regenerative powers and my own creative process; it'll be born again out of the ashes; there'll be a rebirth of language. And I also think that I'm braver at trying different forms. You know, it was only recently that I started to write what we call prose poems in English, or lyrical paragraphs, and now I've written two books in that form, and I've written a second non-fiction book that is coming out in the fall. I'm also working on short stories, which I've never done before. Recently I had two of them published. When I was younger, I wouldn't have been brave enough to risk writing in different genres and sending those pieces out for public scrutiny.

NúRIA: For the online magazine Toque and Canoe?

LORna: No, I'm doing travel pieces for Toque and Canoe, but now I'm writing short fiction as well. And it's scary, because I'm a neophyte, it's as if I'm starting from scratch, knowing nothing. At one point, I considered publishing the stories under a pseudonym so that no one would know I was the writer, 
because it's risky, having no experience in fiction after having been a poet for over forty years. But I'm not going to stop myself because of fear -what do I have to lose? As I get older, I guess I'm more interested and more open and less frightened. I hope so. What if this new writing isn't perfect? Who cares if it isn't perfect? If it gives me pleasure, then why not do it?

NÚRIA: That's really interesting.

LORNA: [laughs] Yeah, I never wrote travel pieces until -was it five years ago?the editor phoned me and said "I think you'd be good at this." She'd just read a nonfiction piece I wrote for one of Canada's national newspapers. I told her I'd never explored travel writing before and didn't have a clue how to start. She said, "Well, give it a try." And I did, and now I love the genre. It's a whole other kind of writing that's opened up for me. I feel like an investigator, a reporter, heading off into the world with my notebook, asking the right person the right question, and observing everything. And she says my travel writing is different from everyone else's on the site, because I come at it as a poet; it's full of images and detail and small anecdotes. She likes what I've come up with and wants me to keep going. I will, because it's fun.

NúRIA: The travel writing took you to writing The Wild in You, right?

LORnA: Yes, it did.

NÚRIA: So, travel writing took you to poetry again, so back and forth.

LORnA: Yeah, exactly. And that was the editor of Toque and Canoe who comes from a journalistic background and doesn't write poetry herself. She sent me to the Great Bear Rainforest on the far west coast of Canada to do an article and told me she was going to introduce me to her friend, Ian McAllister, who's a world-class photographer. Then she added, naïvely I thought, "Why don't the two of you do a book together?" Oh yeah, sure, you think it's that easy? Ian's a famous, extremely busy man; I thought he wouldn't be interested; in fact, maybe I wouldn't be interested. And then we met, we ended up liking each other, and we collaborated. We thank her in the book for match-making, for getting us together. We wouldn't have thought of the partnership on our own.

NÚRIA: What is the role of literature for you at present, both in terms of writing and of reading?

LORNA: From the first time I read a book that had any depth or quality, I knew that reading made me feel more alive and less alone. That was a startling discovery. And I still get a chill when I read something and say, "Ah, I've always known that, but I've never heard it said that way before." That kind of recognition brings reader and writer together; we're both reminded that, for all of our differences, we're part of one species. We share the same emotions; we suffer, we love, we grieve, we laugh. 
And of course, on top of the content is the way the language is used to express the common human truths that form our lives. In the best of writing these can't be expressed in any other way. They have a profundity, a beauty, a clarity particular to each poem or story or novel. The writers' craft, the ability to use those twenty-six letters of the alphabet in a fresh and startling way make the old stories new again. I read serious literature for that zing of recognition and for the beauty of the language that makes the connection between one person and another all the more multifaceted and acute. So, I read to be less alone and to wallow in the deliciousness of the words, laid alongside each other on the page.

Why do I write? Maybe to be less alone too, although I don't think of my reader or the audience when my fingers touch the keyboard. My audience, when I'm in the act of writing, is, finally, the best part of me. I'm writing to the person I want to be -the person that is smarter, funnier, kinder, more philosophic and articulate, that shadow or luminous being that sits behind my computer screen and says: "You can do better than that, that's a cliché, you can go deeper, you can say something more interesting than what you just said." When readers connect with my work, I love it; it's such a warm feeling. It's why I'm keen on giving poetry readings, because when you put out a book, you don't know how those who buy it are reacting to it. But when you present your poems orally and you hear that wonderful, peculiar silence that comes after someone hears a poem, it's an indescribable feeling. You know the listeners "get it." They get something from the words you wrote, and when the poem speaks to them, they can hardly breathe. They fall into a well of deep listening. The writer senses that. The audience's response ripples forward towards the writer and the writer can't help but think this poem is doing something good in the world! This poem is as valuable as an orange, maybe; it satisfies someone's thirst, taste, desire for orange-ness. The poem becomes a living, breathing thing, because the writer's breath sends it out into the air, to the ears of those in the room. The poems vibrate inside the listeners and they and the poem have a visceral, physical connection. In my experience, poems do that more than any other genre. I've sat at many book launches where novelists or nonfiction authors read from their books, and it's just not the same thing. They don't elicit the same somatic response from those in the audience. That's partly because poetry is an oral art; it's meant to be read out loud and to be heard because it is, above all else, music. As a writer, I delight in creating the sonic effects that poetry can achieve. Just like a carpenter who builds a beautiful chair -he must feel wonderful when the first person sits in it, and he hears the creak and sees the body take the shape a body should take in a well-made chair: that's what happens when a well-made poem stands in a room and makes itself available for someone to ease into it. There's the pleasure a writer feels when a reader or listener settles into the language, the images. You hope your work changes people; maybe not in the big ways, but in smaller ways that maybe accrue into something larger. 
NúRIA: Do you think our own perceptions of ageing may change depending on the ways we see the ageing process reflected in literature?

Lorna: Oh, yes, most definitely. Or I should say, at least I hope so. There's a lot of ageism in North-American culture right now. I'm not sure of European. My sense is that a European woman can still be considered beautiful even if she's older, but that's not the case in North America. Part of that is the terrible influence that the United States has on the world and perhaps especially on Canada, its closest neighbour. In US popular culture, for example, most of the female actors you see on screen have had face lifts. What you encounter in a movie is a woman who's playing a character who is supposed to be fiftyyears old, but whose face looks like a thirty-five-year-old's; it doesn't have any lines or character. Whereas British actors like Judi Dench or Helen Mirren have age etched into their skin. As a woman watching a film with a British star, I can exclaim, "Oh, she doesn't look that different from me!" When I watch someone like Jane Fonda on the other hand, I say: "Her body is perfect, her face is perfect, she's seventy-nine or eighty. Why don't I look like that?" It's not a comforting thing; it makes you feel lesser as a human being. I think that literature, which is a more serious art form than popular film, takes us to a place with more honesty and import. It shows us that older people still feel, and worry, and love, and care, and spark with desire, even within the shell of wrinkled skin and a saggy body.

In my culture older people are invisible; the younger eye casts over them and does not see who they are. That person in a restaurant, that old man might have been a neurosurgeon; yet what people see is merely an old man, not someone who saved people's lives because of the deftness of his hands, his years of study, and his magnificent mind. It's so easy to erase someone when their face is puckered and ragged. If we read literature, hopefully some written by older people as well as by younger people with great imaginations and empathy, we'll see the real human being behind that pleated skin. [I just finished a collection of stories called Olive, Again by the fiction writer Elizabeth Strout. The collection made me feel elated because the heroine is a woman in her seventies, and she ages to her eighties by the final story. She is difficult, irascible, and oh so human! On the one hand after the death of her husband, who was always kinder than she, she falls in love unexpectedly with a retired professor; on the other hand, she worries about leaky bowels and takes the difficult step of looking for adult diapers in the pharmacy. How could such stories make me feel elated? The writer really saw her main character; she looked beyond the physical without leaving the physical behind and gave us a rare and luminous look at an old woman, who is bigger than life but at the same time, life itself.]

There's a wonderful song called "Hello in There" by the American folk singer and songwriter John Prine, one of my favourites. He talks about meeting an old person on the street, and instead of walking by, says "Hello in there, hello." In that greeting he acknowledges there is a human being of value inside that frail aged body. It's a beautiful anthem, "hello in there," 
for ageing people. I get very annoyed when those I don't know, waitresses, store clerks, bank tellers, call me dear. They would not call a forty-year-old woman, dear. It's a diminutive, a lack of respect. I've suddenly become an old dear? They have no idea what is raging inside me. It's like a little pat on my head.

NúRIA: Like a child.

Lorna: Like a child. And I want to say to them "I am not your dear." But I don't bother, because why am I going to upset my day or their day?

NúrIA: Okay. And what about quality of life and ageing? What does the term "Quality of life" mean to you?

LORNA: I have to realize that I'm speaking from a first-world perspective. I'm very privileged, because I don't have to worry about clothing myself, feeding myself or seeking shelter; people who come from other places, who come from poverty, those things I take for granted are still huge concerns for them. From my privileged position I can say that quality of life for me involves being able to think clearly, to meet with my friends and make new friends, to be physical in one way or another; if I can't run, I can walk. I need to be active to keep the oils in my body running, my engine running. Quality of life? I'm very lucky to have a house that has a garden, a benefit that is not unusual in Canada but I know it might be in Europe. I have a big garden, and to be out there among the vegetables, to be feeding my fish in the fishpond, to walk with my cat through the paths between the trees is a dream and something that I'm afraid I may have to give up someday because I won't be able to do the work anymore. Right now, though, and for the near future, I can handle it.

And I have the privilege of having an ample space to live in, which again I guess might be a Canadian thing. I have a house with more than enough rooms. I live in the country, where there are no street lights, where I can look at the sky and see the stars. I'm very, very lucky and I'm aware of that. My husband and I were never rich, but we saved whatever money we made in order to buy a house with a substantial piece of property because we both loved to be outside. And we needed our separate working spaces in the house because we were both professional writers. We needed to avoid getting into each other's hair or we'd get grumpy. We needed our privacy, so that's what we worked toward from the time we got together.

NúRIA: It makes sense.

LoRNA: Yeah, good wine, good food, [laughs], good friends.

NúRIA: [laughs] Well, it would be never-ending, eh?

LORNA: Good jewelry, [laughs]. 
Núria: Right.

LorNA: Oh, and did I mention health, I should say health. I'm taking my health for granted, and as an older person, I should not take it for granted.

NúrIA: Old and not so old, you know.

LORNA: [laughs]

NúRIA: Okay, and how do you assess your own quality of life?

LORNA: Some mornings I wake up and say: "Oh, how wonderful! I have another day ahead of me." I hope that I'll continue to feel that way. Other days, since my husband died, I wake up sad and overcome with loneliness, but I try to shake that feeling: I remind myself I'm going for coffee with a friend, I'm going to the gym, I'm going to walk with my cat in the garden. When I can look forward to small things like that, I'm prevented from saying, "Oh, no, another day, and all that's happening is that I'm getting older." That would be terribly depressing. And I can also pull myself out of bed and say: "I'm going to work on a couple of poems today, I'm going to revise a poem today, or start a new short story and see where it takes me." I don't know what I'd do without my writing. I don't know how I'd survive without my writing, without being a writer, without getting up with a writing project in mind. A tonic for me, an elixir, is thinking, "Maybe I'll write a poem today." That's so exciting to me.

NúRIA: That's a very nice quote: "I don't know how I would survive without my writing." And not just for professional writers, but also for amateur writers, right? Because I do believe in the healing properties of writing, even though you may write something and it heals your neighbor. But then your neighbor writes something that you read and it heals you.

LORNA: I think that's lovely, and it acknowledges who you are within the community.

NÚRIA: Even though we can observe both changes in subject matter and new approaches to pre-established themes in your work, there are some symbols and themes that you have used throughout your career. What is it that drives you to continue writing about these career-long topics and symbols?

LORNA: The landscape we grow up in, the landscape of our childhood gets embedded in us. The minerals of the water we drink come from the place we were born and where we spent our lives as children, those minerals form our bones. We are physically and psychically shaped by where our mothers gave birth to us and that place will never leave us. The big skies of the prairie, the absence of trees, the long, cold, white winters are inside me. When I'm writing and imagining a landscape for the setting of my poems, more often than not it will be the prairies.

When I decided to re-write the Old Testament, from a feminist and pagan perspective, the landscape was Saskatchewan, and not British Columbia though I was living in British Columbia and had been there for over a 
decade. That choice made sense on a logical level because the Biblical stories are desert stories, and Saskatchewan gets fifteen inches of rain a year, it's really a desert too. Thus, it was an easy thing to conflate the regions. But, along with that, my interior life is set in the geography of my childhood more than the rainforest where I've lived the last thirty years. Pretty soon I'll have lived more years on the coast than on the prairies. I don't know if things in my writing will shift then or not. I doubt it, because I really do believe that the well that you drink from as a child remains the source that feeds your thirst, and waters your tongue, and makes you speak the way you do, in poetry and in conversation.

NÚRIA: Would you say breaking away with traditional prairie mindsets has played an important role in your work?

LORNA: I grew up really in the patriarchy. I certainly felt that in my house with my mother and my father. My father, for instance, was often unemployed; he worked in the oil fields and when winter would set in and the ground would freeze, he'd be laid off. And it would be very difficult for him and my mother to pay the rent. Very hard for her to figure out how she was going to put groceries on the table. Yet, he didn't want his wife to work. He said: "No wife of mine will work." And so, when she went out and got a job cleaning houses for wealthier people, and then selling tickets at the swimming pool and for the hockey games, he was very angry. His wife working shattered his male pride. He wouldn't have wanted any of his friends to know he alone couldn't support his family.

And I remember as a child -I was eight years old when she went out to work- I remember observing this and thinking something's wrong with this picture, we need the money. It did my mother a world of good to get out of the house. My father was very selfish. She'd ask for five dollars for grocery money, and he'd slide a five-dollar bill across the table and then pull it back, and she'd have to ask again. As a child, I said to myself: "This is never going to happen to me." His power games and their effect on her, made me swear that no matter what, I would be an independent woman, I would get an education, I would never rely on anyone, especially a man, for money. And it also made me look at the world differently, and to put my sense of that injustice in my writing. To vocalize that women have not been given an equal place in my society, in literature, in the workforce, in the mythology, in the stories, in the Bible. What can I do to set that right? What can I do to tell the other side of the stories we were exposed to, the side that women did not get to tell before?

I grew up in a society where women's narratives were not part of what we studied in the schools or read in the literature; they were considered lesser. And it became a goal of mine, that I would explore the perspective of those who were silenced or made invisible, the points of view of women, of the underclass, of the working class, of animals, to tell the stories of what it meant to live in a family like mine and not a middle-class or upper-class 
family. I didn't find them in books, I didn't see my father in books, and I wanted to write about him, too.

NúRIA: How does re-envisioning childhood memories in young-old age contribute to creativity?

LORNA: Memory is such a strange and wonderful thing. I don't know if you remember reading the part in my memoir in which Patrick and I are sitting around talking about our first memory. And I said, my very first memory is my mother stabbing a lizard in the back in the cellar.

NúRIA: Ah, yes, I remember that.

Lorna: And Patrick said to me, "Lorna, you don't have lizards in Saskatchewan. It'd have been a salamander, it'd have been three-inches long. It wouldn't have been a foot and a half." I argued and argued and argued that it was my memory, that it was a lizard, and that my mother had been so strong, and had put a butcher knife in its back and opened the furnace door and thrown it in. Patrick said, "Phone your mum and ask her if it was a lizard." And I did, and she said, "What are you talking about? I wouldn't have done anything like that." I would have sworn in a court room that that was my first memory, yet my mother said it didn't happen. I've come to realize that what I think I remember I may have invented; I may have dreamt. But it doesn't really matter. That memory still informs how I saw my mother, how I thought she was this powerful woman who could slay dragons. Even though she tells me she didn't do it, I think she did it. I hold that image firmly in my mind, in spite of her denial. Memories, as you move further away from the inciting incident, you revise them even more. So, you can't trust what you think might have happened. What you have to trust is the story you created out of your past, and how central it is to your way of being and the way that you see other people in your life. Whether it happened or not is of no consequence. It's my story, part of who I was as a kid and who I became as an adult. Therefore, I'm going to hang on to it. When I write, certainly non-fiction, I'm drawing on what I think of as my memory, but I might be drawing on invention. And memory is at least eighty per cent invention.

NúrIA: So, the other day you said something very interesting about wisdom. You said something that it was, I believe, actually very wise: "I don't think I'm wise because I don't have the answers to everything." In my view, that's precisely the point of being wise, acknowledging your lack of knowledge. So, what is your opinion on the common association of old age with wisdom?

LORNA: One of the advantages of old age is that you can dare to admit your failings, your gaps of understanding; that you can dare to be silly, you can dare to say, "I don't know. Why are you asking me? I have no answers to anything even though I've lived longer than you." And I think that willingness to $\mathrm{dwell}$ in uncertainty is part, too, of being a poet. The German poet Rainer Maria Rilke said that poetry doesn't try to give you an answer. It tries to 
shine a light on the questions. And I believe that profoundly. That's what poetry does. It says, "Let's look at this question again. What is the meaning of life? What is love? How will life end? How will I go on?" Poetry makes you ask those questions in a new way, in a deeper way, but it doesn't try to give you the answer. And I think it's a relief to be older and say, "I don't know." Patrick and I both said that to his children, his two sons whom I'm closest to, who are in their forties now. "Why are you asking us?" we'd say. "We don't know anything." And we were able to live with that and to be comfortable with saying that. It's a release, it's a release.

NúRIA: And why do you think it's a release?

LORNA: Well, if you know all the answers, you've stopped searching. If you know all the answers, you're not asking the right questions, because the most profound questions are the ones we don't have a clue how to answer.

NúRIA: That's a very good one. And in relation to wisdom and old age, what is your view on mentorship? Have you ever been a literary mentor? Have you received literary mentorship?

LORNA: At an early point in my career, there were a couple of writers who were a decade older than me who believed in what I was doing, and who said, "You're a fine writer." I needed someone to affirm that I had talent because I didn't have any self-confidence. So, that was crucial. I've been a mentor to dozens, and dozens, and dozens of younger writers, partly because I was a teacher at a university for some twenty-five years. And those students that showed a spark, I wanted to help them in their careers and in their understanding of what good writing was; I wanted to give them a boost over the wall into some kind of success, and I still am in touch with them. Probably one of the sweetest things is that two of Canada's most well-known novelists, who began as poets, said that Patrick's and my life was also a mentorship to them. Because they saw how two writers could live together and be supportive, not envious or jealous. The way we lived -independent but passionate about each other as well as about our art- became a kind of role modelling for them.

I enjoy working with people who are at the beginning or middle of their careers. One of my tasks is to affirm their talent, because I know how much I needed that affirmation, but I also want to challenge them to become better and to work harder at their craft, to get over laziness or the common complaint that there's no time for writing. A real writer always finds time for writing, no matter what's happening in their day-to-day life. I think mentorship is important. I didn't have a lot of it, but I give a lot of it.

NúRIA: And finally, old age and gender. Do you think there are differences in the way the ageing process is experienced according to gender? Why, or why not?

LORNA: Unfortunately, as women we are more conscious of our bodies and body image. At age ten, eleven, twelve, we already want to lose weight; we already 
wish our legs were longer, and our breasts were bigger or smaller; we are never happy with what we have, even if we're beautiful young people. Only later when we look back at photographs of ourselves from years ago, we think, "Why was that young woman so hard on herself? She looks beautiful." And, unfortunately, I think that self-criticism, that negativity drags through to when you're older. You look at yourself and say, "Oh, my gosh, I'm so saggy, my breasts are saggy, my face is wrinkled, even my earlobes are droopy. Do I look like this? Why aren't I looking like the women in magazines who are my age?" But they all have facelifts, or they weren't in the sun when they were children, and they didn't get sun damage. I think that men do not have that problem for the most part. My husband and our friends his age are examples. I have a very good friend who just turned eighty-one and we've been emailing back and forth, and I said something like "I'm an old woman now and I'm conscious of my body's decline, the loss of beauty, the sore knees, etc." And he said, "I don't feel that way at all." And he's ten years older than me. He said, "Men don't feel that way. We still think that we're younger, that we're a catch. That any woman would be happy to be with us." He said it jokingly, but there's truth in it.

I don't remember my husband, who was nine years older than me, ever being concerned about the way he looked until he was ill. I, on the other hand, was. And he was sweet enough to reassure me. But I didn't have to reassure him. He just felt he was a good-looking guy walking through the world whether he was seventy-nine or forty-nine. He never had that problem. I wish, I wish we as women could have the same confidence, I wish we would just love who we are and the way we look. Whether we're stocky or skinny; whether we have legs that are long or short; whether our breasts are large or small. I wish we'd just learn to love ourselves. One of my poems, "News Flash from the Fashion Magazines" was about that, right? Let's worship breasts no matter what they are shaped like. The refrain is "breasts are back" and when I read the poem, I ask women in the audience to shout the line and they join in with gusto. You don't have to have a perfect Vanity Fair breast that can't support a pencil underneath it, or that it fits into a champagne glass instead of a beer mug. Let's say bullshit to that. Let's say, whatever breasts I have are beautiful. I am beautiful. As women, we'd be much happier if we could say that to ourselves.

NúRIA: Indeed. And the last question, are there any specific experiences about both male and female ageing that you find more relevant to write about in your work?

LORNA: My work, since I started writing, has been at least partly autobiographical. So, I write about what is intriguing me at the moment; what's bugging me at the moment. I don't write about something because I think it's an issue I should explore. I write about what takes me away and then I figure out later what it is I'm trying to say. I go into the poem the way you would stand on the top of a mountain in a pair of skis and I push myself off into the snow: 
I might fall, I might hit a tree, I might break a leg; I never know what's going to happen. I never know the end point of the poem.

In the process of writing, I'm not able to say in an academic way, well this poem is dealing with ... an abstract term. I just go into it because I have to try to understand something. And I understand something through searching for words, in a poetic way. I go into the language, the rhythms and the music. I never start with an abstract idea or an issue. I hope my poems are full of interesting ideas, but they usually don't begin there. They begin in a more sensory place. There's a Canadian poet from a generation before mine who said, "Wanting to write a poem is like having an interior itch that you have to scratch." I love that. That best describes the urge, the need, to write a poem. I know when the feeling's coming and then I just sit down at my desk and see what's going to happen next.

NúRIA: So, maybe now you write more about ageing...

LORNA: Because I'm ageing, because I'm old in anyone's definition. So, yes now I'm writing about being an old woman. Being in a body that is not my youthful body. Hoping that my knees don't start aching so much that I can't walk like I used to. Not looking at myself in a bathroom mirror in a hotel room, where the lights are so brutal and unforgiving. "Ah! Who's that person? It can't be me!" Not worrying about how many lines I have in my face. That's what I'll be writing because that's who I am, and my poems embody who I am, and my body embodies my poems. And whether that's because I'm female or it's just me, I don't know.

NúRIA: I love that quote. "My poems embody who I am, and my body embodies my poems."

LORNA: I'd never said that before, you brought it out of me.

NÚRIA: Well, this is the end of the interview. Thank you so much, Lorna, for your time and patience.

LORNA: You're welcome. 